\title{
José Jurado Morales, Carmen Martín Gaite, el juego de la vida y la literatura, Madrid, Visor, 2018, 256 pp.
}

Cita sugerida: Leuci, V. (2021). [Revisión del libro

Carmen Martín Gaite, el juego de la vida y la literatura de J. Jurado Morales]. Olivar, 21(33), e099. https://doi.org/10.24215/18524478e099

El libro de José Jurado Morales, Carmen Martín Gaite, el juego de la vida y la literatura, del 2018, nace como señala el autor - como fruto de una vida dedicada al estudio de la obra de Carmen Martín Gaite. Desde la lectura fundacional y primera de Entre visillos, el crítico da cuenta de su periplo como lector, primero, por los derroteros extensos de la polifacética autora: comenzando por su narrativa, prosiguiendo por sus ensayos e investigaciones, hasta dar luego con su poco explorada cara poética y con sus trabajos como traductora. Este camino por la fecunda producción de la salmantina fue iluminado en todo momento por una mirada bivalente, en el cruce entre la vida y la literatura; binomio inseparable e insoslayable en las propias concepciones artísticas de la autora, que Jurado Morales elige, en la senda de Gaite, para titular sus páginas: “a sabiendas del sentido lúdico de la vida y de la literatura (...). A Martín Gaite le gustaba el juego de la vida y 
se divertía con el juego de la escritura y la lectura" (p. 12). Ahora bien, este trayecto y esta fascinación como lector desembocaron posteriormente en una pródiga producción crítica en libros y artículos, entre los que se cuentan Del testimonio al intimismo: los cuentos de Carmen Martín Gaite (1925-2000) (2001), La trayectoria narrativa de Carmen Martín Gaite (2003), y una colección abundante de conferencias, artículos, capítulos, etc., producidos a lo largo de años de estudio, que se hallaban dispersos y diseminados y que el presente libro se propone agrupar.

El volumen se divide en una Introducción y seis grandes bloques, subdivididos a su vez en capítulos referidos a temáticas diversas dentro de la biografía y de la vasta producción de la autora. Ha sido mencionada la intrínseca cercanía y conexión entre vida y escritura en Carmen Martín Gaite, una biografía que se entrecruza de modo irrenunciable con su obra, estableciendo una relación de reciprocidad que atraviesa las múltiples caras de su literatura. Asimismo, destaca Jurado que más allá de este nítido cruce entre vida y escritura, es fundamental advertir el carácter permeable de los diferentes géneros explorados por la autora; el conjunto de su literatura ofrece al lector una "consistencia compacta", una "interrelación trabada entre los distintos géneros que cultiva" y una "coherencia de su pensamiento" que expone en sus trabajos ensayísticos y recrea en sus ficciones (p.40). En este sentido, es importante subrayar que también los capítulos y secciones que componen el libro se interrelacionan y nutren mutuamente, presentándose como lados complementarios de un mapa poliédrico, de costados múltiples que se exploran y se van imbricando a lo largo de las páginas del estudio.

En primer término, el bloque inicial se denomina "El fundamento autobiográfico", y se subdivide a la vez en tres partes subtituladas “Tentativas autobiográficas”, "Experiencia vital y escritura poética” y "Un viaje a El cuarto de atrás". Como indica el propio crítico, este primer bloque es el que presenta mayor afinidad y cercanía con el título del volumen, ya que en él se analizan las caras de su escritura más vinculadas con su experiencia vital, buscando establecer asimismo los motivos y búsquedas que alientan tal conexión. El capítulo primero se detendrá en su narrativa, constatando a través de elementos extratextuales los diversos grados en que la biografía ingresa en sus novelas, en busca del autoconocimiento y de la pretensión de crear ficciones cercanas a su propia individualidad e intimidad. En este mismo sentido, pero explorando otro cauce genérico, el segundo capítulo dará cuenta de la obra poética de Gaite; una de las vertientes menos conocidas de la autora, que acompaña en su cronología los derroteros biográficos, enlace que incluso lleva a Jurado a considerar esa labor intermitente pero constante - a rachas, tal el título de su poemario- como una "biografía de su intimidad" (p. 14). Finalmente, como cierre, la tercera sección se detiene en una de las novelas más importantes de la autora, considerada el culmen de su narrativa, El cuarto de atrás, para dar cuenta de la confluencia de matrices diversas y complementarias que entraman esta novela en el cruce de lo autobiográfico, las memorias, lo metaficcional, el género fantástico, etc.

Por su lado, el bloque siguiente, "Amistad y literatura: Ignacio Aldecoa”, se detiene, como anuncia su paratexto, en uno de los vínculos más importantes e influyentes en la trayectoria vital e intelectual de la salmantina: su amistad con Aldecoa. Aquí, a través de los dos capítulos denominados "A modo de homenaje: Esperando el porvenir" y "Los pasos encontrados de Martín Gaite e Ignacio Aldecoa”, el interés radica en presentar las conexiones entre ambos escritores y el influjo decisivo del vitoriano en la obra de Gaite. Para ello, se revisan testimonios y evocaciones personales, que — al decir de la propia autora- están "a medio camino entre el libro de memoria y el comentario por libre” (p. 15), a través del repaso por cuatro conferencias de la autora que rinden homenaje tanto a Aldecoa como a su generación. Por su parte, el capítulo segundo desbrozará los lazos humanos y literarios entre ambos, en sus más de veinte años de amistad, desde el arranque de sus estudios académicos en la Universidad de Salamanca hasta el fallecimiento de Aldecoa, dando cuenta de la importancia de una de sus personas más admiradas en el camino biográfico y escriturario de la salmantina.

Como indica Jurado, este bloque está puesto deliberadamente como pórtico a los siguientes que espigarán los diversos géneros trabajados por Gaite, en especial para situarnos en el momento en que arranca su trayectoria y enfatizar los vínculos con el autor. En este sentido, el siguiente bloque suscribe sin duda la idea 
de afinidad y deuda entre ambos, al referirse a uno de los géneros predilectos de Aldecoa y en que se aventuró también exitosamente Martín Gaite: los cuentos. Bajo el título general de "Etapas de aprendizaje: cuentos del medio siglo", este segmento se subdivide en dos partes en que se analiza su incursión por este género, obligado ejercicio para todos los aspirantes a novelistas de acuerdo a una difundida idea de mediados de siglo (p. 16). Aquí, el crítico realizará una aproximación en primer término al primero de los cuentos de Gaite, "Un día de libertad", de 1953, para advertir a través de esa escritura germinal principios constructivos que se proyectarán en escritos posteriores, a la vez que se tenderán lazos con posibles influencias propias de la época: Camus, Sartre o Kafka, principalmente. Por su lado, el segundo capítulo, bajo el rótulo "Algo más que cuentos de mujeres", se aboca - como nos anticipa el paratexto- a un interés y matriz recurrente e ineludible en la obra de la autora: el universo de la mujer y lo femenino. No obstante, a partir del análisis y el recorrido por la presencia de la mujer y de personajes femeninos en los cuentos de la autora, el crítico reflexiona que dicha presencia excede la mera presentación de la mujer para proyectarse, de manera más amplia, hacia un orden mayor, como "sinécdoque del conjunto de la sociedad española de posguerra" (p. 129).

El cuarto bloque se ocupará de uno de los géneros más trabajados por la escritora, luego de la novela: el ensayo. La reflexión ensayística acompasará su camino intelectual, con cavilaciones que iluminan temas diversos, a los que se referirá el autor en cada uno de los cuatro capítulos en que se desglosa el conjunto titulado "El arte de pensar". El interlocutor, primero, el papel del lector, en menor medida pero presente también, son algunas de las cuestiones sobre las que la autora elucubró en sus trabajos y que conciernen al primer capítulo, "La entrada en el castillo: una poética del lector", un texto inédito de Jurado escrito en el año 2000. Por su lado, el siguiente estudio se detiene en otra de las preocupaciones nucleares de Gaite, la temporalidad, a partir del repaso de las diversas aristas que presenta esta temática compleja en relación con su propia vida, con los marcos temporales de sus ficciones y con las diversas temporalidades por las que transita en sus ensayos y trabajos de investigación, desglosados bajo las coordenadas del tiempo soñado (siglo XIII), tiempo imaginado (siglo XVIII) y tiempo vivido (siglo XX). En referencia a estos cortes cronológicos, el siglo XVIII adquiere en la producción de la autora un papel primordial, del que se da cuenta en el capítulo siguiente, "Sobre los Usos amorosos del dieciocho en España". Allí, se aludirá al cortejo como práctica amorosa, que Martín Gaite analiza desde una perspectiva de gran originalidad y carácter pionero, y, asimismo, se pretende mostrar su interés sostenido por este período, que dio como fruto su tesis doctoral de 1972, a partir de nociones recurrentes en su obra: la lengua, la comunicación, el lenguaje y la mujer. Por último, en una senda intermedia, el capítulo final de la sección continúa con la mirada ensayística pero no para hablar de los ensayos de Gaite, sino para analizar algunas de las claves de su narrativa revelando, al decir de Jurado, "una concepción de la literatura y modo de narrar próximos a la esencia de todo ensayo" (p. 20), desbrozadas finamente en "La narrativa de Martín Gaite o la esencia misma del ensayo".

El quinto bloque enfocará su visión en la novelística, género rutilante en la polifacética producción de la salmantina. "Las novelas de la supervivencia" se bifurcará pues en dos capítulos referidos a su novela Lo raro es vivir, el primero, y a la póstuma Los parentescos, el segundo. En primer lugar, "De vida y literatura existencial: Lo raro es vivir" estudia dicha novela en diálogo, primero, con el contexto filosófico existencial de la época que Gaite conoce y sería determinante en su redacción. Así, el análisis de diversos niveles narrativos del texto se nutre de este conocimiento para dar cuenta de un enfoque existencial, tejido por otro lado a las experiencias vitales de la autora. Luego, "Mundo interior y sociedad posmoderna: Los parentescos" se centra en este texto final para dar cuenta de rasgos en su creación afines a la posmodernidad y a su planteamiento respecto de la subjetividad; y, asimismo, se establecen vínculos entre su protagonista y las propias peripecias vitales de Martín Gaite, entrecruzando - como marca ineludible en la autora- vida y literatura.

Sobre el final, el sexto bloque constituye una sección sumamente valiosa dentro del volumen, al realizar un repaso y comentario por la profusa bibliografía publicada sobre Carmen Martín Gaite hasta su muerte en el año 2000. Con el elocuente marbete de "Texto sobre texto", el autor se aboca a este ejercicio invalorable de 
presentar y sopesar la extensa producción bibliográfica que atraviesa medio siglo de reflexión y crítica, en este caso, dando cuenta entonces de "miradas ajenas" dedicadas a lo largo de décadas a la escritura de la autora.

Los catorce capítulos compilados en el texto, finalmente, ordenados por cronología y afinidades temáticas o genéricas, traslucen — como decíamos al inicio- un interés pronunciado y sostenido a lo largo de una vida de lectura y reflexión sobre la producción de la salmantina. Ellos, publicados anteriormente como capítulos, conferencia, artículos, etc., sumados a escritos inéditos, representan indudablemente un lúcido y valioso aporte para la aproximación a la escritura de Gaite. Cada estudio revela un saber pormenorizado, riguroso y sutil de los temas y textos analizados. No obstante, a su vez, desde una visión global, los diversos capítulos en su conjunto reflejan un conocimiento profundo de la autora, de su biografía intelectual y vital, y de los cuantiosos temas, obsesiones e intereses que se entraman en su obra polifacética, posicionando tanto a este libro como a su autor como faro y referente indiscutible para el estudio del fecundo universo de Carmen Martín Gaite. 